\title{
Video-enhanced visualization of the larynx and intubation with the Bullard laryngoscope - equipment report
}

\author{
[La visualisation, facilitée par vidéo, du larynx et de l'intubation avec le \\ laryngoscope Bullard - une analyse de matériel]
}

Alexander Dullenkopf MD, Goran Lamesic, Andreas Gerber MD, Markus Weiss MD

Purpose: A simple technical solution is presented to provide video transmission from the tip of a Bullard laryngoscope to a bedside video display, while the operator is still able to look through the viewing ocular of the Bullard laryngoscope during tracheal intubation.

Equipment: This is achieved by insertion of an ultrathin fibreoptic video-endoscopic system into the working channel of the Bullard laryngoscope. Thereby the view from the distal blade tip is transmitted to a bedside monitor, without interfering with the use of the Bullards laryngoscope's original eyepiece. The presented technical solution allows video transmission without considerable additional weight normally associated with attaching video endoscopy cameras, light and camera cables to endoscopic devices. Thus, the Bullard laryngoscope remains lightweight and easy to maneuver. A screw-threaded adapter with a side-port is proposed to prevent displacement of the fibreoptic cable while still allowing application of oxygen.

Conclusion: Experience and skills with tracheal intubation using the presented video-enhanced Bullard laryngoscope can be achieved in the originally intended way, while the supervisor or attending viewers can follow the tracheal intubation procedure on the video display.

Objectif : Nous présentons une solution technique simple pour fournir la transmission vidéo, à partir de la pointe d'un laryngoscope Bullard jusqu'à un écran de chevet, alors que l'opérateur peut encore regarder au travers de l'oculaire du laryngoscope Bullard pendant l'intubation endotrachéale.
Matériel : Cette manœuvre est possible par l'insertion d'un système d'examen fibroscopique vidéo dans un canal du laryngoscope Bullard. Ainsi, la vue provenant de la pointe de la lame est transmise sans interférence au moniteur de chevet avec l'usage de l'oculaire original du laryngoscope Bullard. La solution technique présentée permet la transmission vidéo sans le poids considérable normalement ajouté par les caméras vidéoendoscopiques, la lumière et les câbles de caméra attachés au dispositif endoscopique. Le laryngoscope Bullard est donc léger et facile à manipuler. Un adaptateur fileté comportant un orifice latéral est suggéré pour prévenir le déplacement du câble fibroscopique tout en permettant l'administration d'oxygène.

Conclusion : On peut développer les aptitudes et l'expérience nécessaires à l'intubation endotrachéale en utilisant le laryngoscope Bullard, avec facilitation vidéo, de la façon originalement prévue pendant que le superviseur ou les thérapeutes observateurs peuvent suivre l'intubation endotrachéale à l'écran vidéo.

$\mathrm{I}$ $\mathrm{N}$ patients with known or expected difficult tracheal intubation, intubation with a fibreoptic bronchoscope, with or without video endoscopic monitoring, is the standard of care. ${ }^{1}$ When unanticipated difficulties with tracheal intubation arise in the anesthetized patient, the Bullard laryngoscope (BL; Circon Corporation, Stamford, CT, USA) is a simple rigid endoscopic intubation laryngoscope for rapid endoscopic assistance. ${ }^{2,3}$ Among many endoscopic intubation laryngoscopes (Uphser scope, Wu scope, Kawahara scope $)^{4-6}$ the BL has become the most com-

From the Department of Anaesthesia, University Children's Hospital, Zurich, Switzerland.

Address correspondence to: Dr. Markus Weiss, Department of Anaesthesia, University Children's Hospital, Steinwiesstrasse 75, 8032 Zurich, Switzerland. Phone: +41 1266 71 11; Fax: +41 126679 94; E-mail: markus.weiss@kispi.unizh.ch

Financial disclosure statement: The Bullard laryngoscope, the flexible fibreoptic endoscope and the video-endoscopy monitoring equipment are standard equipment of our PICU and anesthesia unit.

Accepted for publication December 10, 2002.

Revision accepted February 12, 2003. 


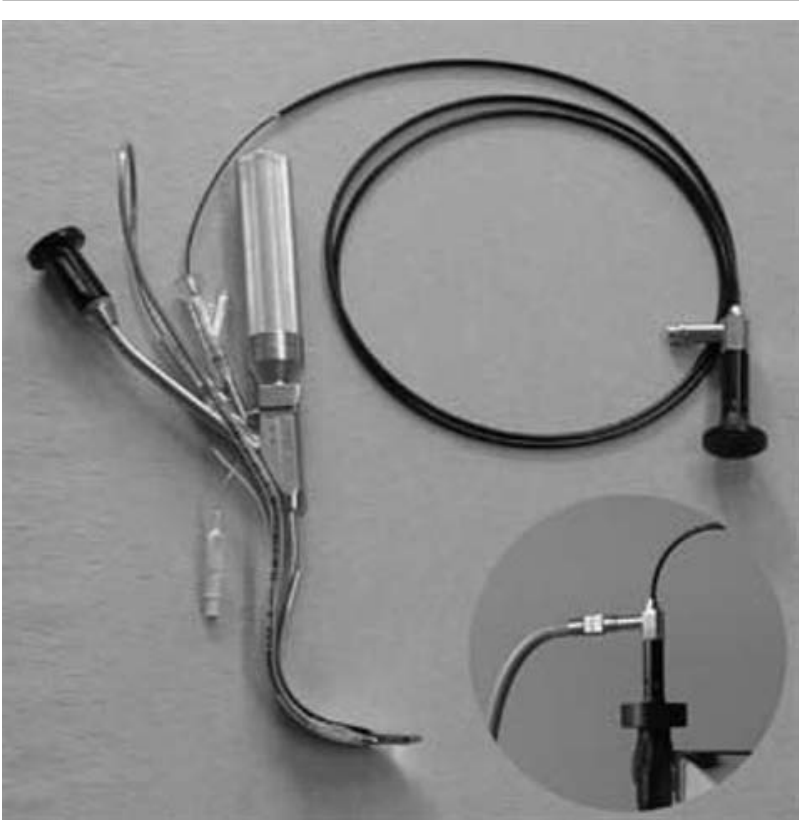

FIGURE 1 Bullard laryngoscope (adult version) with non-malleable stylet and mounted endotracheal tube. A small fibreoptic endoscope (OD $1.9 \mathrm{~mm}$ ) is inserted into the working channel and locked with a screwing mechanism attached to the proximal opening of the suction channel. The view from the blade tip is transmitted to the endoscope viewing ocular, which is attached to a video endoscopy camera and a light source cable.

mon tested endoscopic alternative device for difficult tracheal intubation in children and adult patients. ${ }^{7-12}$ As with fibreoptic bronchoscopes, a standard video endoscopy camera can be attached to the eyepiece of the $\mathrm{BL}$ to give a picture from the blade tip to a bedside monitor. ${ }^{13-15}$ Video transmission of the endoscopic view has been reported to facilitate demonstration, teaching and supervision of fibreoptic procedures and to improve learning curves in novices. ${ }^{16}$ However, video endoscopic equipment is not always available, particularly in the emergency situation. Thus, the user should be trained to use the BL without video-transmission, as proposed originally. We present a technical solution for videotransmission of the view from the tip of the BL for teaching and supervizing purposes while the operator is looking through the eyepiece during intubation.

\section{Description of equipment}

The $\mathrm{BL}$ is a curved rigid fibreoptic intubation device. ${ }^{17,18}$ It consists of a conventional laryngoscope battery handle with light source and a unique anatomically s-shaped blade. The laryngoscope has incorpo-

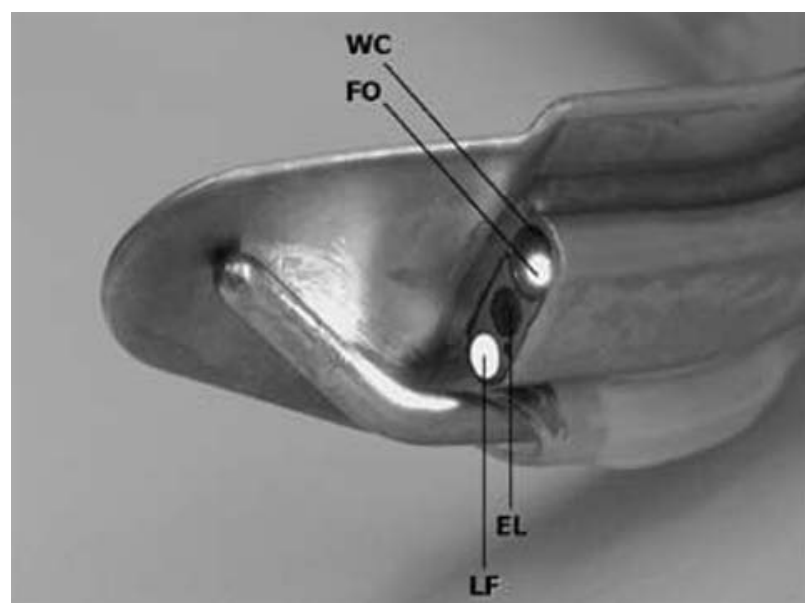

FIGURE 2 Distal blade tip of the Bullard laryngoscope (BL) with incorporated light fibres for airway illumination (LF), original endoscopic lens (EL) of the BL for image transmission and distal opening of the working channel (WC). The distal lens of the inserted fibreoptic endoscope (FO) ends at distal working channel opening.

rated fibreoptic bundles for both airway illumination and transmission of the view from the distal blade tip to the proximal viewing eyepiece. The viewing eyepiece allows to attach a conventional video endoscopy camera, and the battery light source handle can be replaced by a handle allowing the connection of a light cable from an external light source. ${ }^{13}$ The blade's shape was designed to allow tracheal intubation with as little neck mobilization as possible and requiring minimal mouth opening. ${ }^{19}$ The operator looks through the eyepiece to visualize the glottic opening and to direct the tracheal tube into the trachea. Different techniques are described for insertion of the tracheal tube with the BL. ${ }^{19,20} \mathrm{~A}$ further feature of the $\mathrm{BL}$ includes a $3.7-\mathrm{mm}$ working channel incorporated into the laryngoscope that allows suctioning and application of oxygen and local anesthetics. The proximal end of the channel is equipped with a Luer-lock connector for attachment of a three-way stopcock. ${ }^{19}$

We modified the BL to allow video transmission of the tip view and simultaneous viewing through the eyepiece by the operator. An ultrathin fibreoptic video endoscopic image transmission system (Acutronic Medical Systems AG, Baar, Switzerland) is inserted into the working channel of the laryngoscope (Figures 1 and 2). This fibreoptic video endoscopic system is normally used in our neonatal intensive care unit to check for tracheal tube position and tube obstruction. By means of a locking mechanism (Tuohy-Borst, 


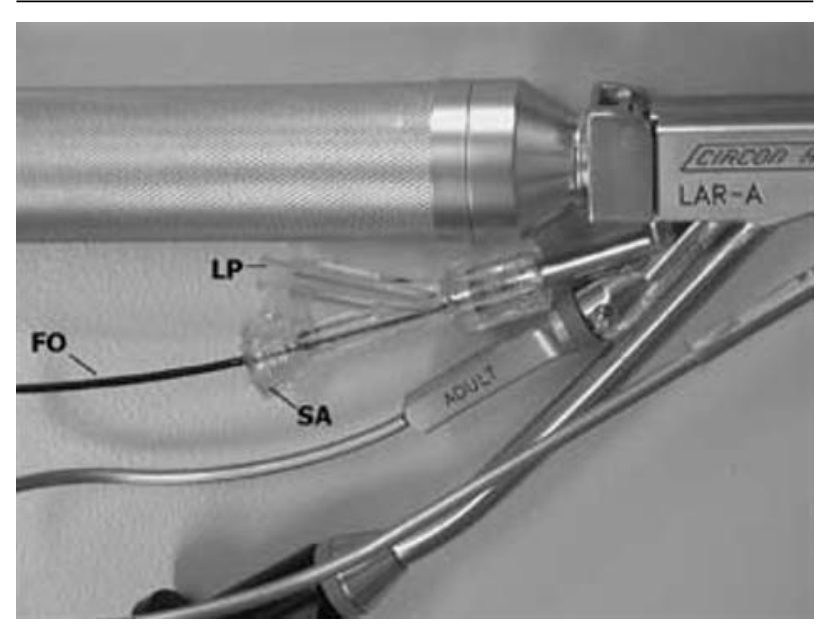

FIGURE 3 Bullard laryngoscope with plastic screwing adapter mounted to the proximal port of the working channel. The screwthreaded adapter (SA) allows to lock the fibreoptic endoscope (FO) within the working channel to prevent rotational and longitudinal displacement. Oxygen can still be applied to the lateral port of the plastic adapter (LP).

PTBY-RA, William Cook Europe, Bjaeverskov, DK) attached to the proximal port of the working channel, rotational and longitudinal displacement of the fibreoptic endoscope is prevented. In addition, oxygen can be applied by the lateral port of the adapter (Figure $3)$. The thin flexible fibrescope carries image transmission fibres (10'000 pixels) and light fibres for airway illumination. The endoscope has an outer diameter of $1.9 \mathrm{~mm}$ in the distal part and is $1.8 \mathrm{~m}$ in length. Total weight of the flexible endoscope including the eyepiece is $95 \mathrm{~g}$. The viewing ocular of the inserted fibreoptic endoscope is attached to a standard ocular video-camera system (Figures 1 and 4 ). In addition, the light cable adapter of the flexible endoscope can be connected to a light source to improve airway illumination through the procedure. Intubation is performed by the operator in the originally intended way while the fibre endoscope provides on-line transmission of the endoscopic view for the instructor or additional viewers (Figure 4).

\section{Discussion}

In contrast to modern devices whereby a video-camera is incorporated in the tip or the head of the flexible endoscope, conventional rigid or flexible endoscopic devices with a viewing ocular necessitate the attachment of a video endoscope camera and sometimes of a light

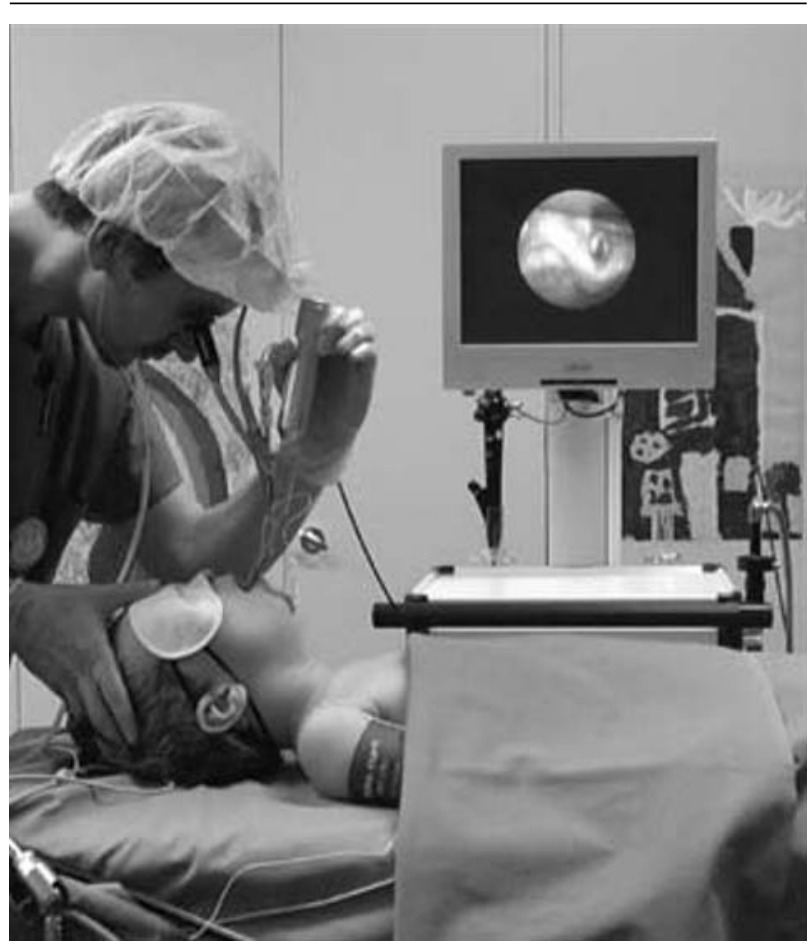

FIGURE 4 Tracheal intubation using the video-enhanced Bullard laryngoscope while the operator visualizes the vocal cords through the eyepiece, and the instructor can follow the intubation procedure on the monitor (photograph reproduced with parental permission).

cable for video endoscopy. As a result, the weight of the camera, camera cable and light cable limits the maneuverability of the endoscopic device. In addition it does not enable the intubator to use the eyepiece while the teacher follows the intubation procedure on the monitor. By coupling a teaching attachment to the eyepiece, the instructor can follow the procedure on a second eyepiece or a video-camera. ${ }^{21}$ However, with all these attachments, the maneuverability of the device is considerably reduced.

To overcome these limitations, we employ a long thin flexible video endoscopic system, which provides a view from the distal tip of the BL. The endoscopic device is lightweight and easy to maneuver. The underlying principle is that video transmission from the tip of the rigid diagnostic or therapeutic device can be obtained easily by insertion of a small fibreoptic endoscope through an incorporated optic channel. This concept has been reported to be useful for video laryngoscopy or video otoscopy. ${ }^{21-26}$

The flexible endoscope, without a steering mechanism or a channel for suction or application of drugs 
or oxygen remains relatively inexpensive (Can $\$ 2,000$ ) and is easy to clean. The ocular of the flexible endoscopic system can be attached to most currently available video endoscopy systems. Such a universally applicable video transmission cable in combination with a compact video endoscopic monitor-system attached to the anesthetic working station may also provide rapid endoscopic assistance to verify or adjust the position of various airway devices such as tracheal tubes, laryngeal mask airways or double lumen tubes.

In conclusion, insertion of a simple flexible endoscope into the working channel of the BL allows training of tracheal intubation in the way intended originally (via the eyepiece), while the instructor can follow the procedure on a monitor.

\section{References}

1 American Society of Anesthesiologists Task Force. Practice guidelines for management of the difficult airway. A report by the American Society of Anesthesiologists Task Force. Anesthesiology 1993; 78: 597-602.

2 Gorback MS. Management of the challenging airway with the Bullard laryngoscope. J Clin Anesth 1991; 3: 473-7.

3 Kiefer G, Hentrich B. The Bullard laryngoscope. An aid in unforseen difficult intubation (German). Anaesthesist 1996: 45: 70-4.

4 Pearce AC, Shaw S, Macklin S. Evaluation of the Upsherscope. A new rigid fibrescope. Anaesthesia 1996; 51: 561-4.

$5 W u T$, Chou H. A new laryngoscope: the combination intubating device (Letter). Anesthesiology 1994; 81: 1085-7.

6 Kawahara M, Takeshita T, Akita S. A new model of laryngoscope equipped with fiberoptics. Anesth Prog 1989; 36: 70-1.

7 Araki K, Nomura R, Tsuchiya N, Yoshikawa $\Upsilon$. Cardiovascular responses to endotracheal intubation with the Bullard and the Macintosh laryngoscopes (Letter). Can J Anesth 2002; 49: 526.

8 Shulman GB, Connelly NR. A comparison of the Bullard laryngoscope versus the flexible fiberoptic bronchoscope during intubation in patients afforded inline stabilization. J Clin Anesth 2001; 13: 182-5.

9 Weiss M, Schwarz U, Gerber AC. Difficult airway management: comparison of the Bullard laryngoscope with the video-optical intubation stylet. Can J Anesth 2000; 47: 280-4.

10 Hastings RH, Vigil AC, Hanna R, Yang BY, Sartoris $D J$. Cervical spine movement during laryngoscopy with the Bullard, Macintosh, and Miller laryngoscopes. Anesthesiology 1995; 82: 859-69.

11 Watts $A D$, Gelb AW, Bach DB, Pelz DM. Comparison of the Bullard and Macintosh laryngoscopes for endotracheal intubation of patients with a potential cervical spine injury. Anesthesiology 1997; 87: 1335-42.

12 Shulman B, Connelly NR. The adult Bullard laryngoscope as an alternative to the Wis-Hipple $1^{1 / 2}$ in paediatric patients. Paediatr Anaesth 2000; 10: 41-5.

13 Crosby ET. Techniques using the Bullard laryngoscope (Letter). Anesth Analg 1995; 81: 1311-20.

14 Dubin SA, McDonald K. Video display for teaching fiberoptic intubations (Letter). Anesthesiology 1989; 71: 167.

15 Pittman SK, Parnass SM, El-Ganzouri A, Braverman $B$. Video-assisted fiberoptic endotracheal intubation (Letter). Anesth Analg 1994; 78: 197-9.

16 Smith JE, Jackson AP, Hurdley J, Clifton PJ. Learning curves for fibreoptic nasotracheal intubation when using the endoscopic video camera. Anaesthesia 1997; 52: 101-6.

17 Bjoraker DG. The Bullard intubating laryngoscopes. Anesthesiol Rev 1990; 17: 64-70.

18 Borland LM, Casselbrant M. The Bullard laryngoscope. A new indirect oral laryngoscope (pediatric version). Anesth Analg 1990; 70: 105-8.

19 Cooper SD, Benumof JL, Ozaki GT. Evaluation of the Bullard laryngoscope using the new intubating stylet: comparison with conventional laryngoscopy. Anesth Analg 1994; 79: 965-70.

20 Ringwalt EC. Use of a guide wire to facilitate tracheal intubation with the Bullard laryngoscope (Letter). Anesthesiology 1998; 89: 805.

21 Katz RL, Berci G. The optical stylet - a new intubation technique for adults and children with specific reference to teaching. Anesthesiology 1979: 51: 251-4.

22 Shorten GD, Roberts JT. Some applications of fiberoptics in anesthesia. Anesthesiol Clin North America 1991; 9: 187-93.

23 Haas JE, Tsueda K. Direct laryngoscopy with the aid of a fiberoptic bronchoscope for tracheal intubation (Letter). Anesth Analg 1996; 82: 438.

24 Weiss M, Schwarz U, Dillier CM, Gerber AC. Teaching and supervising tracheal intubation in paediatric patients using videolaryngoscopy. Paediatr Anaesth 2001; 11: 343-8.

25 Dullenkopf A, Holzmann D, Feurer R, Gerber A, Weiss $M$. Tracheal intubation in children with Morquio syndrome using the angulated video-intubation laryngoscope. Can J Anesth 2002; 49: 198-202.

26 Weiss $M$, Holzmann D. Fiberoptic video-otoscope. The Laryngoscope (in press). 